\title{
Study on Gas Emission Prediction of Steeply Inclined Coal Seam Applied Horizontal Slice Mining
}

\author{
Huang Xuchao ${ }^{1}$, Fan Cheng ${ }^{2}$, Wang Rui ${ }^{3^{*}}$ and Yan Guoqiang ${ }^{4}$ \\ ${ }^{1}$ China Coal Technology Engineering Group Chongqing Research Institute, Xinjiang Branch, Urumchi, Xinjiang 830091, China \\ ${ }^{2}$ College of Mining and Safety Engineering, Shandong University of Science and Technology, Qingdao 266590, China \\ ${ }^{3}$ College of Mechanical and Electronic Engineering, China University of Petroleum, Qingdao 266580, China \\ ${ }^{4}$ Institute of Applied Geosciences, Karlsruhe Institute of Technology, Karlsruhe 76131, Germany
}

Received 13January 2019; Accepted 27 May 2019

\begin{abstract}
Calculation of emission quantities from different gas emission sources is important to predict gas emission quantity on the horizontally layered working face of a steep seam. However, existing gas emission prediction model has many problems, such as complicated calculation links, poor accuracy and non-applicability to the steep seam. In this study, a model applicable to predict gas emission from horizontal mining layer of steep seam was constructed based on the different-source prediction method. This model was applied to the west wing working face in the 45\# seam of WuDong Mine in Xinjiang Autonomous Region in China. Prediction results of this model were compared with existing standard data of the different-source prediction method. According to analysis results, existing different-source prediction model is optimized specifically and the proposed model adds predictions of pressure relief gas emission in coal mass below the mining seam and gas emission in top goaf. The calculated gas emission in the working face presents an error of $+8.63 \%$ with actual gas emission. This error conforms to the practical situation of horizontal layered mining of steep seam and verified the reliability of the proposed model. Conclusions obtained in this study serve as theoretical references to gas emission prediction in horizontal mining layer of steep seam.
\end{abstract}

Keywords: Steep coal seam, Gas emission, Source prediction method

\section{Introduction}

With the advancement of coal mining equipment and coal mining technologies, backward blasting mining, high-grade conventional mining and other mining technologies have been gradually replaced by comprehensive mechanized coal mining. In production practices, the high mining intensity and high advancing speed of the fully mechanized top coal caving cause complicated gas emission, large emission quantity and uneven emission quantity on the working face, thus increasing the probability of occurrence of gas accidents. Particularly, the accident of transfinite gas is extremely prominent. According to statistics, the proportion of steep seam in total mined seams in coal mines in Western China is higher than $50 \%$ [1]. Among them, Xinjiang is an important large coal production base with hundred millions of tons of coal reserves and accounts for more than $30 \%$ of steep seam reserves in the global reserves [2-3].The severity of gas disasters also threats the normal mining of working faces. As an important factor that influences coal mine safety production, gas disaster is a concern in researches on mineral industry [4-5]. According to statistics of relevant national departments by 2017, the occurrence of gas explosion accidents accounts for $31.9 \%$ of coal accidents in the current stage. Therefore, studying characteristics of gas emission to reduce occurrence of gas accidents on the

*E-mail address: hxc2001@163.com

ISSN: $1791-2377$ @ 2019 Eastern Macedonia and Thrace Institute of Technology. All rights reserved. doi:10.25103/jestr.122.03 working face and further eliminate gas accidents is vital to prevent gas accidents on working face of coals.

Gas emission on working face is divided into ordinary emission and outburst. Many scholars mainly concentrated in gas outburst on working face. In the process of gas outburst, major influencing factors of outburst intensity are geostress and gas contents in coal seams [6]. The internal energy of gas, the principal energy source of gas accident [7], makes the maximum principal stress at the free face close to the coal wall deviate from the perpendicular direction gradually. Moreover, stress vectors are connected into an arc protruded toward the deep positions of coal wall [8], thus triggering the occurrence of gas outburst accidents of the working face. Nevertheless, ordinary gas emission on working face has to be explored to prevent gas accidents on the working face. Therefore, it is of extremely importance to predict gas emission on working face accurately in advance.

\section{State of the Art}

Prediction of gas emission quantity is a key factor in actual mine and mining area design, gas management and gas extraction design. It is an important gas disaster prevention and control means in coal mines; thus, prediction accuracy is crucial in achieving the safety production and economic benefit of coal mines $[9,10]$. Substantial studies on gas emission prediction focused on mine statistical analysis, gas content, and different source prediction methods $[4,11]$. With respect to the mine statistical analysis method, Karacan 
et al. [12] determined the location of gas coal formation by prospecting holes. They performed single variable statistics and semi-variation function analysis by using data of different strata to determine the distribution and continuity of parameters, such as gas content. However, the early drilling process required time-consuming preparation to realize the mathematical modeling and prediction of gas emission based on the mine statistical analysis method, hence further restricting field applications. Liu et al. [13] discovered problems in the calculation formula of the change gradient $(\alpha)$ of relative gas emission with mining depth. Therefore, the mathematical model to calculate $\alpha$ based on relative gas emission was deduced again using the statistical analysis method and the statistical principle of least squares method. However, the prediction results of gas emission obtain a large error in practical measurement. With respect to the gas content method, Palchik et al. [14] disclosed the relationship of natural gas content with time and internal fracture intensity in rock formations, considering that natural gas outbursts in rock formation easily caused risks when a shallow subway tunnel construction must run through a shallow gas-bearing sandstone. However, they indirectly predicted natural gas emission, which inevitably caused great prediction errors. Based on the original gas pressure in coal seam, the laboratory-tested constant, and the industrial analysis results of coal adsorption, $\mathrm{Hu}$ et al. [15] indirectly predicted gas content by optimizing the Langmuir equation. However, this method must be further applied to a field test due to the short study period and few field applications. Dai et al. [16] predicted gas emission in mines using the mining (including surrounding rocks) and adjacent layers via the differentsource prediction method. On the basis of the calculation formula of different gas source terms, gas emission on the working face could be predicted quickly and accurately with a small relative error in measured data. Based on the above studies, results of the mine statistical analysis and gas content methods are less accurate than that of the different source prediction method, which is attributed to the complexity of field. This finding demonstrates that the different source prediction method is a gas emission prediction method with higher speed, higher accuracy, and more extensive applicability compared with the mine statistical analysis and gas content methods.

To increase the accuracy of the gas prediction model, Huang et al. [17] proposed a nonlinear combined prediction method of gas emission based on the support vector machine (SVM). This method was compared with the combined index regression based on measured data, hyperbolic regression, grey 3 single predictions, and the neural network nonlinear method. Results demonstrated that this nonlinear combined prediction method achieved higher prediction accuracy and lower prediction risks compared with other prediction methods. Based on the combination of the mine statistical analysis method and multiple influencing factors (including geographical factors), Zhang et al. [18] proposed a new method to predict mine gas emission based on a gas geological mathematical model by using mathematics theory I as the modeling tool. This method was successfully applied to a mine site, and its validity was verified by comparing prediction results with measurement results. Based on the principal component analysis (PCA), Lv et al. [19] selectedoriginal gas content in coal seam, buried depth of coal seam, coal thickness, coal bed pitch, and length of working face from the 12 influencing factors of gas emission on working face and used them to predict gas emission on multiple working faces via a multi-step linear regression method. These five components effectively increased the prediction accuracy. However, the prediction results of different working faces have great errors in measurement results. Based on the sequential observation data of gas emission on the stope face, $\mathrm{He}$ et al. [20] calculated and analyzed the correlation dimension of time sequences and predicted gas emission on working faces. However, results showed that the gas emission system of the stope face was a nonlinear chaos system with a complicated structure. Multiple independent variables and a kinetic equation calculation were required to describe the system and eventually predict the gas emission of the working face. Heather et al. [21] used the artificial neural network (ANN) as the basic principle and used MCP software to predict gas emission through a $\mathrm{C}++$ programming of the dynamic linkage library of MS AccessTM. The MCP software first analyzed the geological conditional database of mines through PCA, which simplified the analysis database. Then, the maximum influencing parameters that ANN had to process were determined. Finally, gas emission on the working face could be predicted. The whole process required high professional computer knowledge, thus restricting field operation and calculations.

Regarding the optimization of existing gas prediction models, Li et al. [22] focused on low prediction accuracy due to excessive prediction indexes and improved the prediction accuracy of a model through the coupling effect of factor analysis and a back propagation (BP) neural network. However, many factors were considered in a prediction process, resulting in the heavy calculation workload. Considering the influencing factors of gas emission on the working face, Guo et al. [23] optimized the multi-element prediction model using the gradual regression analysis method and finally constructed a mathematical model for gas emission prediction which presented high prediction accuracy. Patrick et al. [24] determined the relationships among gas content, gas components and spatial parameters based on a case study on coal seams the South Basin mines in Sydney by considering local geographic space conditions (e.g. hydrological characteristics and geological structure) as influencing factors. Based on the least square prior regression method, they optimized the empirical formula for gas emission prediction. However, using geographic space conditions as influencing factors requires highly accurate instruments or data to determine the accuracy of geographic space data. From the perspective of gas emission mechanism, Roland et al. [25] analyzed and concluded that air leakage in goaf diffused adsorbed gas in the surrounding rock formation. The relationship between gas concentration on the working face and time was optimized on the basis of gas flow equilibrium equation, thereby obtaining the prediction formula of gas emission on the working face. However, effects of surrounding rocks and gas emission in the adjacent layer on the gas emission in the working face were ignored, further causing large prediction errors. Some scholars constructed a gas emission model by integrating multiple mathematical functions and methods. For example, Fan et al. [26] obtained product function (PF) components from the local mean decomposition method based on historical data of absolute gas emission in a field investigation and performed extrapolation speculation for each component through SVM functional fitting. Finally, the prediction results of different PF components were overlapped and reconstructed, thus obtaining a gas emission prediction model. $\mathrm{Hu}$ et al. [27] calculated and analyzed a 
statistical sample database involving gas emission in the stope face and relevant influencing factors through 11 regularized outlier isolation and regression, with isolation of abnormal noise interference of samples. Moreover, the optimized prediction model of gas emission in the stope face was constructed by combining the teaching-learning-based optimization of regression parameters. Fu et al. [28] constructed a gas emission prediction model by combining the ant colony clustering algorithm and Elman neural network. They obtained the optimal weight and threshold of the Elman neural network and increased the prediction accuracy of the Elman neural network by maximizing the ant colony clustering algorithm, thereby realizing the dynamic prediction of gas emission in the stope face. Li et al. [29] constructed a gas prediction model by integrating multiple methods. On the basis of the weighted strategic function applicable to the characteristics of a gas emission system, the least squares SVM was improved, and parameters were optimized by the genetic algorithm. Prediction error residues were corrected by the state transfer probability and the prediction, accuracy of the proposed model was improved.

These studies focus on single coal seam or horizontal, approximately horizontal and gently inclined seams, but none of them is proven by application in steep seams. Gas emission in the working face is significantly different from that in the horizontal and gently inclined seams due to complexity and uniqueness of mining technology, mine pressure distribution and gas emission sources in steep seams. Few studies on gas emission rule and gas emission prediction in fully mechanized caving faces of steep seams are currently available. Therefore, the different-source prediction method meets the requirements of gas emission prediction of steep seams from the perspective of principles. Some scholars have discussed gas emission prediction methods, but the relevant gas emission models have disadvantages of impracticability and poor operation and cannot meet requirements on field gas prediction.

The 43\# and 45\# coal seams in Wudong Coal Mine of Shenhua (Xinjiang) Energy Co., Ltd are steep and extremely thick coal seams where fully mechanized top coal caving technology is adopted. As the mining depth increases, gas pressure and content at the coal seam also increase. The present stopping level is $+575 \mathrm{~m}$, and recent gas disasters directly affect the safety production and economic benefit of the coal mine. Therefore, directing at deficiencies of existing studies, the present work proposed a prediction method of gas emission quantity with the west-wing working face at the $45 \#$ coal seam of Wudong Coal Mine as the study object. The method was applicable to steep seam mining. The basis for the prediction of pressure-relief gas emission quantity at the lower mining layer and that in the goaf at the roof was added with existing standard different-source prediction methods to guarantee the prediction accuracy of gas emission quantity at the steep seam. The obtained results were then compared with those obtained through existing standard different-source prediction methods, which provided a theoretical basis for the application of prediction methods of gas emission quantity in steep seam mining.

The remainder of this study is organized as follows. Section 3 expounds the calculation of gas emission quantities at the $43 \#$ and $45 \#$ steep seams in Wudong Coal Mine using the different-source prediction method. Section 4 compares the gas emission quantity solved using the newly established prediction method and those obtained through standard prediction methods, and then discusses the comparison results. Section 5 summarizes this study results and related conclusions.

\section{Methodology}

\subsection{Overview of research methods}

The different source prediction method uses the gas content from each source as the prediction basis. This method considers the following two factors: gas content in the coal seam and several geographical natural factors (e.g., geological structure, coal seam dip angle and other coal seam occurrence conditions) and mining technological factors (e.g., mining method, mining technique, and production process) related to the coal seam. Among these factors, gas content in the coal seam is the main influencing aspect of gas emission volume. The widely accepted composition relationship of gas emission is shown in Fig. 1.

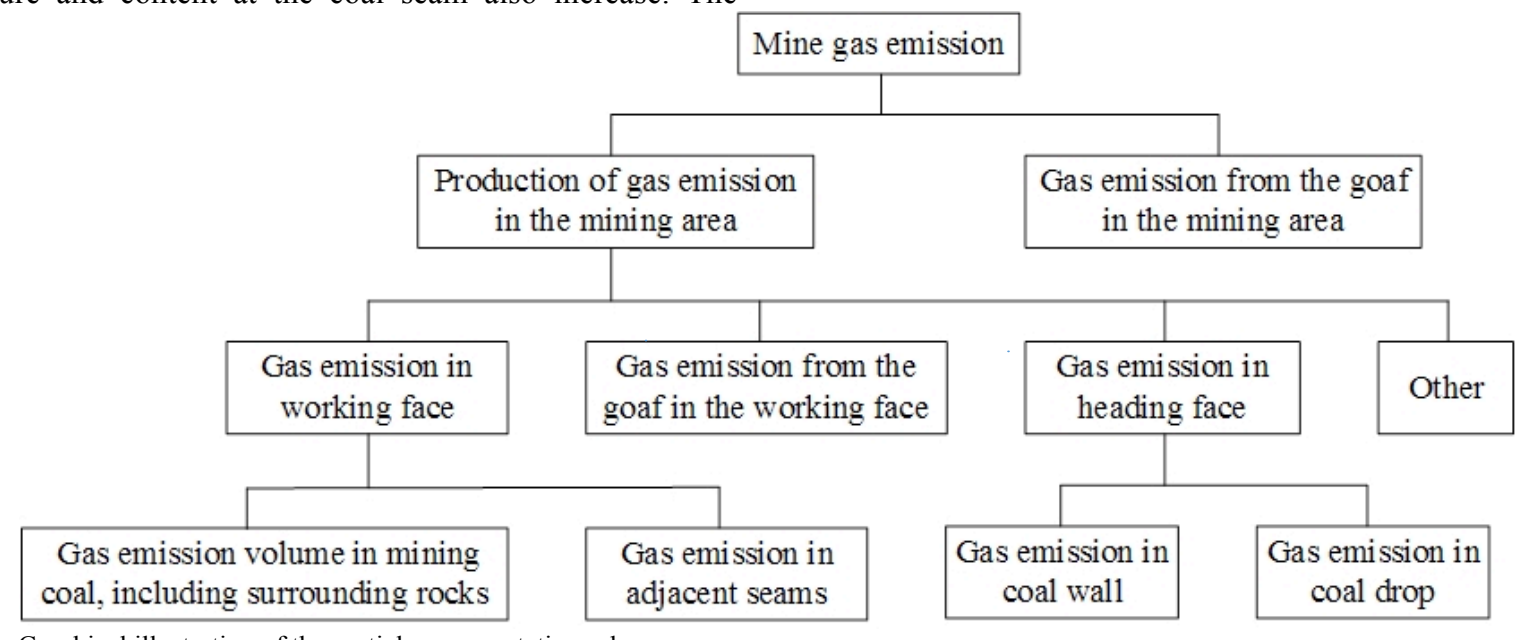

Fig. 1. Graphical illustration of the particle representation scheme

The different source prediction method regulates that gas emissions on the stope face mainly include gas emission volume of the mined bed and the adjacent layer [30]. Stopping technological characteristics and gas emission laws and sources in steep seam were analyzed. Results show that existing standards lack references for pressure relief gas emissions in lower coal bed and gas emission prediction on the top cavity during the stratified mining process. The two parameters were calculated to guarantee the prediction accuracy of the gas emission volume. Calculations of the two types of gas emission volume introduce in this study to ensure prediction accuracy of gas emission volume. The 
Huang Xuchao, Fan Cheng, Wang Rui and Yan Guoqiang/

Journal of Engineering Science and Technology Review 12 (2) (2019) 17 - 26

optimized calculation formula of the total gas emission volume on the working face is as follows:

$q_{\text {mining }}=q_{1}+q_{2}+q_{3}+q_{4}$

where $q_{\text {mining }}$ is the relative gas emission volume of stope face $\left(\mathrm{m}^{3} / \mathrm{t}\right), q_{1}$ is the relative gas emission volume of the mining bed $\left(\mathrm{m}^{3} / \mathrm{t}\right), q_{2}$ is the relative gas emission volume of the adjacent layer $\left(\mathrm{m}^{3} / \mathrm{t}\right), q_{3}$ is the relative gas emission volume in lower coal seams of the mining bed $\left(\mathrm{m}^{3} / \mathrm{t}\right)$, and $q_{4}$ is the relative gas emission volume in goaf in the upper position $\left(\mathrm{m}^{3} / \mathrm{t}\right)$.

\subsection{Gas emission volume during stratified mining}

With reference to Prediction Methods of Gas Emissions in Mine Wells [30] and prediction results of gas emission volume in full-seam mining, the following gas emission volume of the mined bed can be obtained:

$$
q_{1}=K_{1} \times K_{2} \times \frac{m}{m_{0}} \times\left(X_{0}-X_{c}\right)
$$

where $q_{1}$ is the gas emission volume of mining coal, including surrounding rocks but excluding the lower coal seams $\left(\mathrm{m}^{3} / \mathrm{t}\right) ; K_{1}$ is the gas discharge coefficient of surrounding rocks and is 1.2 in full-collapse management of roof; $K_{2}$ is the gas emission coefficient of waste coals on the working face. Here, $K_{1}=1 / \eta$, where $\eta$ is the recovery ratio of the working face. $X_{0}$ and $X_{\mathrm{c}}$ are the gas contents in the original and residual coal seam $\left(\mathrm{m}^{3} / \mathrm{t}\right)$, respectively.

The overall average coal thickness in the $45 \#$ coal seam of Wudong Coal Mine is $27 \mathrm{~m}$. On the west wing at $+575 \mathrm{~m}$ level, the thickness is approximately $22.0 \mathrm{~m}$ on average and the residual gas content is $1.53 \mathrm{~m}^{3} / \mathrm{t}$. This position is $48 \mathrm{~m}$ away from the $0.51 \mathrm{~m}$ thick $44 \#$ coal seam and $73 \mathrm{~m}$ away from the $43 \#$ coal seam. Furthermore, it is $3.6 \mathrm{~m}$ away from the $0.61 \mathrm{~m}$ thick $46 \#$ coal seam and $15 \mathrm{~m}$ away from the 0.46 $\mathrm{m}$ thick $47 \#$ coal seam. Given that the $43 \#$ and $45 \#$ coal seams are simultaneously mined and a large gap exists between the two seams, the gas emission in the $43 \#$ coal seam is overlooked. The mean recovery ratio is calculated according to the recovery ratio during the normal stoping of this steep seam. Relevant data is brought into Equation (2) and results are shown in Table 1.

Table 1. Prediction result of present stratified coal seam in 45 \# coal mine of $575 \mathrm{~m}$ in WuDong coal mine

\begin{tabular}{|c|c|c|c|c|c|c|c|c|}
\hline $\begin{array}{l}\text { Coal } \\
\text { number }\end{array}$ & $\begin{array}{l}\text { The gas } \\
\text { discharge } \\
\text { coefficient of } \\
\text { surrounding } \\
\text { rocks } K_{1}\end{array}$ & $\begin{array}{l}\text { The recovery } \\
\text { ratio of the } \\
\text { working face } \\
\eta\end{array}$ & $\begin{array}{l}\text { The gas } \\
\text { emission } \\
\text { coefficient } \\
\text { of waste } \\
\text { coals on the } \\
\text { working } \\
\text { face } K_{2}\end{array}$ & $\begin{array}{l}\text { The mining } \\
\text { thickness of } \\
\text { the mined } \\
\text { beds } m_{0}(\mathrm{~m})\end{array}$ & $\begin{array}{l}\text { Working face } \\
\text { mining height } \\
m(m)\end{array}$ & $\begin{array}{l}\text { The gas } \\
\text { contents in } \\
\text { the original } \\
\text { coal seam } \\
X_{0}\left(\mathrm{~m}^{3} / \mathrm{t}\right)\end{array}$ & $\begin{array}{l}\text { The gas } \\
\text { contents in } \\
\text { the residual } \\
\text { coal seam } X_{\mathrm{c}} \\
\left(\mathrm{m}^{3} / \mathrm{t}\right)\end{array}$ & $\begin{array}{l}\text { The gas } \\
\text { emission } \\
\text { volume of } \\
\text { mining coal } \\
\boldsymbol{q}_{1}\left(\mathrm{~m}^{3} / \mathrm{t}\right)\end{array}$ \\
\hline 45 & 1.2 & 0.4689 & 2.132651 & 22 & 22 & 2.68 & 1.53 & 2.95 \\
\hline
\end{tabular}

\subsection{Gas emission volume in adjacent layers}

Gas emission volume in adjacent layers can be calculated with reference to Prediction Methods of Gas Emissions in Mine Wells [30]:

$q_{2}=\sum_{i=1}^{n} \frac{m_{i}}{m_{0}} \times \zeta_{i}\left(X_{i}-X_{i c}\right)$

where $q_{2}$ is the gas emission volume in the adjacent layer of the stope face $\left(\mathrm{m}^{3} / \mathrm{t}\right), m_{i}$ is the coal thickness of the adjacent layer $i(\mathrm{~m})$, and $m_{0}$ is the mining thickness of the mined bed (m). $X_{i}$ is the gas content in the adjacent layer $i$ $\left(\mathrm{m}^{3} / \mathrm{t}\right)$ and its value can be selected with reference to the mined bed in the absence of measured data. $X_{i c}$ is the residual gas content in the adjacent layer $\left(\mathrm{m}^{3} / \mathrm{t}\right)$ and its value can be selected with reference to the mined bed in the absence of measured data. $\zeta_{i}$ is the gas emission rate influenced by mining of the adjacent layer $i(\%)$ and its value can be selected with reference to Fig. 2 in the absence of measured data [30].

The prediction results of gas emission of the adjacent layer are shown in Table 2.

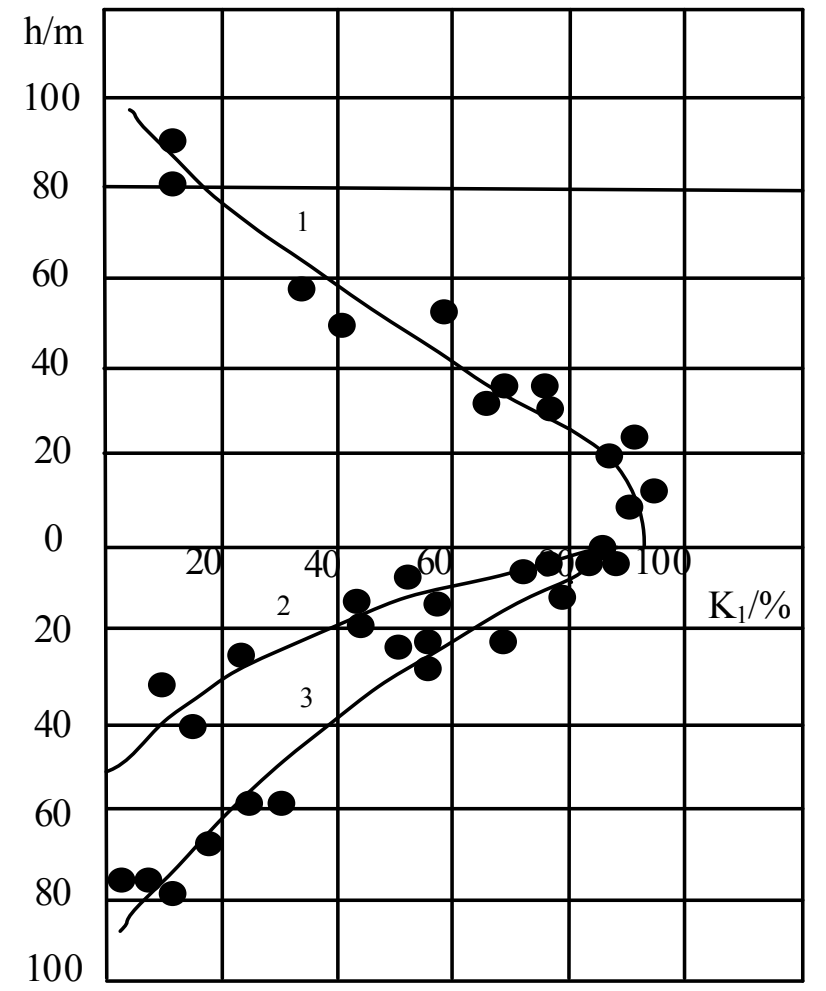

1-Upper adjacent layer; 2-gently inclined lower adjacent seam; 3 - Inclined and steep lower adjacent seam

Fig. 2. Relationship between gas emission rate and layer spacing in adjacent stratum 
Table. 2. Prediction of gas emission from nearby floors

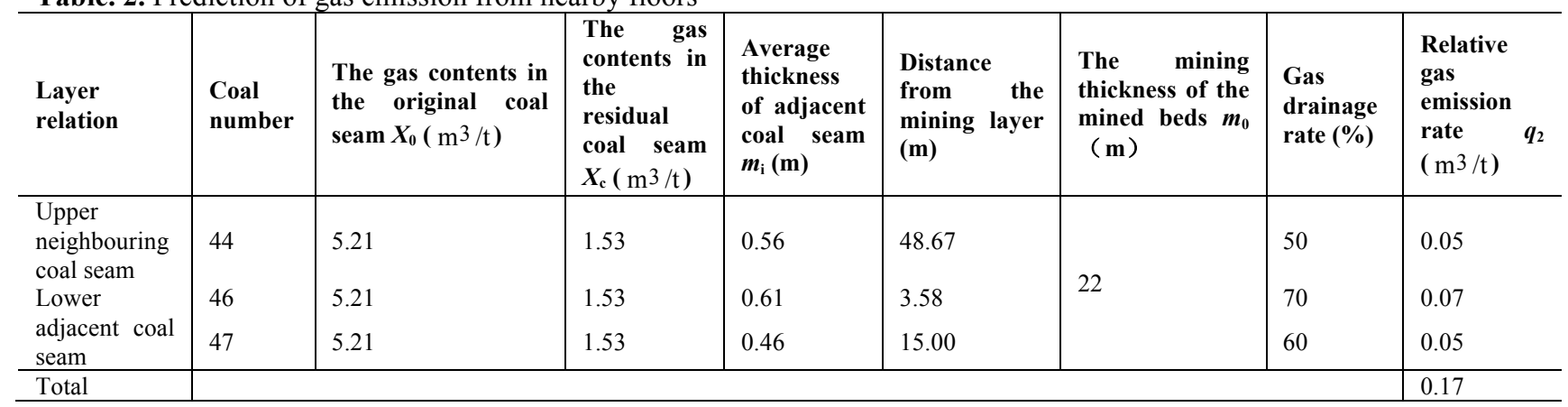

\subsection{Gas emission in lower coal seams during stratified} mining

The gas emission in lower coal seams during stratified mining presents the similar laws as those of gas emission in adjacent layers. However, rock stratum does not exist between the lower and upper coal seams. The two types of gas emission are the secondary distribution of stresses in the original coal rocks caused by stoping of the working face, resulting in the secondary development of cracks in coal rocks. The ventilation negative pressure between the gas pressure and stope face further forms the differential pressure. Gas flows to the stope face through the pores and cracks on the mining and primary rocks. Therefore, the calculation formula of gas emission in lower coal seams can be deduced from the relevant calculation formula in the adjacent layer:

$q_{3}=\sum_{i=1}^{n} \frac{m_{i}}{m_{0}} \times \lambda_{i}\left(X_{i}-X_{i c}\right)$ where $q_{3}$ is the pressure relief gas emission volume in lower coal seams of the stope face $\left(\mathrm{m}^{3} / \mathrm{t}\right), m_{i}$ is the thickness of the lower coal seams (m), $m_{0}$ is the mining thickness of the mined bed $(\mathrm{m}), X_{i}$ is the gas content in the lower coal seams $i\left(\mathrm{~m}^{3} / \mathrm{t}\right), X_{i c}$ is the residual gas content in the lower coal seams $i\left(\mathrm{~m}^{3} / \mathrm{t}\right)$, and $\lambda_{i}$ is the gas emission rate of the lower coal seams $i$ influenced by mining (\%).

The limit of gas emission was determined by numerical analysis and direct measurement of gas content in coal seams. In field tests, gas contents at different distances of the lower coal seams before and after the exploitation of the stope face were measured. The sphere of influence of coal mining was determined by analysis data. The overall arrangement of drilling holes for field test is shown in Fig. 3. Gas content test results and drilling parameters are shown in Tables 3 and 4, respectively.

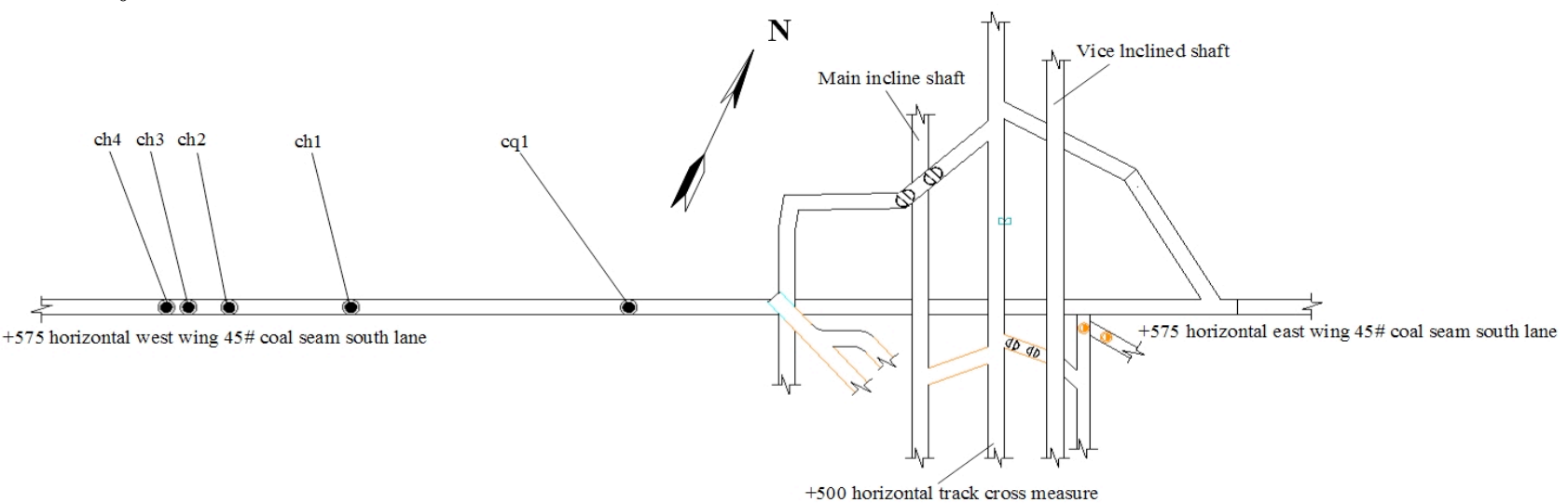

Fig. 3. Coal seam gas content determination point drilling layout map

Table. 3. Gas content determination results

\begin{tabular}{|c|c|c|c|c|c|c|c|}
\hline Time & Number & $\begin{array}{l}\text { Sampling } \\
\text { depth }(m)\end{array}$ & $\begin{array}{l}\text { Sampling } \\
\text { depth }(m)\end{array}$ & $\begin{array}{l}\text { Horizontal } \\
\text { distance from the } \\
\text { stop line }(\mathrm{m})\end{array}$ & $\begin{array}{l}\text { Releasable gas } \\
\text { content }\left(\mathrm{m}^{3} / \mathrm{t}\right)\end{array}$ & $\begin{array}{l}\text { Gas content } \\
\left(\mathrm{m}^{3} / \mathrm{t}\right)\end{array}$ & Remarks \\
\hline $\begin{array}{l}\text { Mining } \\
\text { previous }\end{array}$ & cq1 & $\begin{array}{l}37 \\
67 \\
83.3 \\
\end{array}$ & $\begin{array}{l}522.78 \\
541.25 \\
551.28 \\
\end{array}$ & $\begin{array}{l}53.48 \\
32.62 \\
21.10 \\
\end{array}$ & $\begin{array}{l}4.35 \\
3.47 \\
3.43 \\
\end{array}$ & $\begin{array}{l}5.68 \\
5.00 \\
4.76 \\
\end{array}$ & \\
\hline \multirow{4}{*}{ Mining after } & $\operatorname{ch} 1$ & $\begin{array}{l}35 \\
67 \\
82 \\
\end{array}$ & $\begin{array}{l}524.75 \\
547.38 \\
557.98 \\
\end{array}$ & $\begin{array}{l}-10.28 \\
-16.93 \\
-20.05 \\
\end{array}$ & $\begin{array}{l}4.03 \\
3.06 \\
2.51 \\
\end{array}$ & $\begin{array}{l}5.57 \\
4.59 \\
4.04 \\
\end{array}$ & \\
\hline & $\operatorname{ch} 2$ & 33 & 520.32 & -44.86 & 3.98 & 5.51 & Hole collapse at $57 \mathrm{~m}$ \\
\hline & $\operatorname{ch} 3$ & $\begin{array}{l}33 \\
67 \\
87\end{array}$ & $\begin{array}{l}521.21 \\
543.07 \\
555.92\end{array}$ & $\begin{array}{l}-56.86 \\
-63.93 \\
-68.09 \\
\end{array}$ & $\begin{array}{l}3.91 \\
3.28 \\
2.81 \\
\end{array}$ & $\begin{array}{l}5.44 \\
4.81 \\
4.34 \\
\end{array}$ & \\
\hline & ch4 & 40 & 526.77 & -64.32 & 3.42 & 4.95 & $\begin{array}{l}\text { Connected to the } \\
\text { extraction hole at } 43 \mathrm{~m}\end{array}$ \\
\hline
\end{tabular}

Note: If the stoping line approaches the main shaft, then it is marked positive. In other words, the stoping direction is denoted positive. 
Table 4. Gas content determination results

\begin{tabular}{l|l|l}
\hline Drilling number & Location & Dip $\left(^{\circ}\right)$ \\
\hline cq1 & Located at +500 level 45\# West Wing South Lane inward 45m & 38 \\
ch1 & Located at +500 level 45\# West Wing South Lane inward 128m & 45 \\
ch2 & Located at +500 level 45\# West Wing South Lane inward 163m & 78 \\
ch3 & Located at +500 level 45\# West Wing South Lane inward 175m & 78 \\
ch4 & Located at +500 level 45\# West Wing South Lane inward 181m & 78 \\
\hline
\end{tabular}

Note: Deflection angle refers to the included angle between the roadway strike and drilling holes.

Given that drilling coal samples were basically at different heights, various dip angles of holes were investigated to disclose the distribution law of gas contents at the same height under the influence of pressure relief. Test error due to gas extraction asymmetry was overlooked throughout the study process. Based on the preceding data, the drilling hole ch2 collapsed at $57 \mathrm{~m}$ and the drilling hole ch4 was connected to the gas extraction drilling hole. Moreover, the tested gas content was similar to that in the coal seam at the same height, thereby neglecting the two groups of data. Owing to advanced gas extraction in some lower coal seams before stoping, gas content in the original coal seam cannot be directly used to replace the gas content before the mining. Instead, gas content before the stope line was utilized as the gas content before mining. However, advanced gas extraction was only performed in some lower coal seams and gas content of raw coal was employed in predicting the gas emission volume. The correlation between gas content test data at cql before the stope line and the elevation is shown in Fig. 4.

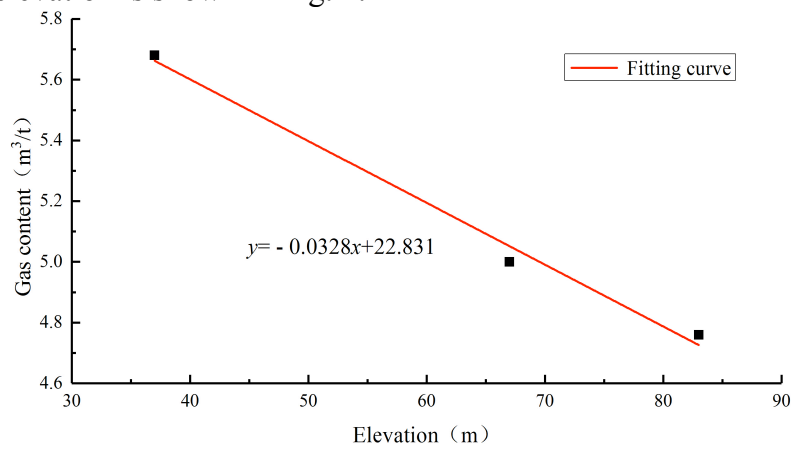

Fig. 4. Gas content and elevation diagram

$y=-0.0328 x+22.831$

where $y$ is the gas content in coal seam $\left(\mathrm{m}^{3} / \mathrm{t}\right)$ and $x$ is the elevation of coal seam $(\mathrm{m})$.

Measured data of drilling gas content and theoretical values in Equation (5) are listed in Table 5. Ch1 and ch3 were two drilling holes with the highest sampling length. However, the coal seam dip angles at the two drilling holes were different. Drilling data at the sampling depth of $67 \mathrm{~m}$ were analyzed to ensure study accuracy. At the $+557 \mathrm{~m}$ level, ch1 was close to the coal seam floor and the error between measured and theoretical values of gas content was $10.8 \%$. Moreover, ch3 was close to the seam roof and the error was $5.6 \%$. This result reflected that the influence depth of the mining of the seam floor was higher than that of the roof. If the error between the measured and theoretical values was higher than $5 \%$, then mining influence could be observed. The error of ch1 on the $+547 \mathrm{~m}$ level was $5.9 \%$, which reflected that the mining influencing depth was approximately $30 \mathrm{~m}$ away from the floor. The error of ch3 on the $+543 \mathrm{~m}$ level was $4.2 \%$; thus, this depth was not influenced by mining activities.

Table 5. Theoretical gas content and measured gas content analysis table

\begin{tabular}{|c|c|c|c|c|c|c|}
\hline Number & Sampling depth (m) & Elevation (m) & $\begin{array}{l}\text { Theoretical coal } \\
\text { seam gas content } \\
\left(\mathrm{m}^{3} / \mathrm{t}\right)\end{array}$ & $\begin{array}{l}\text { Actual measurement } \\
\text { of coal seam gas } \\
\text { content }\left(\mathrm{m}^{3} / \mathrm{t}\right)\end{array}$ & Error (\%) & Remarks \\
\hline cq1 & $\begin{array}{l}35 \\
67 \\
82\end{array}$ & $\begin{array}{l}524.75 \\
547.38 \\
557.98\end{array}$ & $\begin{array}{l}5.62 \\
4.88 \\
4.53 \\
\end{array}$ & $\begin{array}{l}5.57 \\
4.59 \\
4.04 \\
\end{array}$ & $\begin{array}{l}0.9 \\
5.9 \\
10.8\end{array}$ & \\
\hline $\operatorname{ch} 3$ & $\begin{array}{l}33 \\
67 \\
87\end{array}$ & $\begin{array}{l}521.21 \\
543.07 \\
555.92\end{array}$ & $\begin{array}{l}5.68 \\
5.02 \\
4.60\end{array}$ & $\begin{array}{l}5.44 \\
4.81 \\
4.34 \\
\end{array}$ & $\begin{array}{l}4.1 \\
4.2 \\
5.6\end{array}$ & \\
\hline
\end{tabular}

Gas emission rate refers to the ratio between residual gas content influenced by mining and gas content in the original coal seam. According to the previous description, the gas content on the west wing of the $45 \#$ coal seam on the +575 $\mathrm{m}$ level was $5.21 \mathrm{~m}^{3} / \mathrm{t}$ and the residual gas content was $1.53 \mathrm{~m}^{3} / \mathrm{t}$. Based on the preceding studies, the influence depth of upper coal seam mining is approximately $30 \mathrm{~m}$ and the gas emission rate is approximately $29 \%$. Curve 3 in Fig. 5 indicates the relation curve between the gas emission rate and interlayer space. Given the smaller reduction trend of the gas emission rate along the coal seam than that along the rock formation, a few studies on the changes in the gas emission rate along the coal seam direction have been conducted. Thus, the gas emission rate presents a linear distribution along the coal depth, thereby obtaining the following:

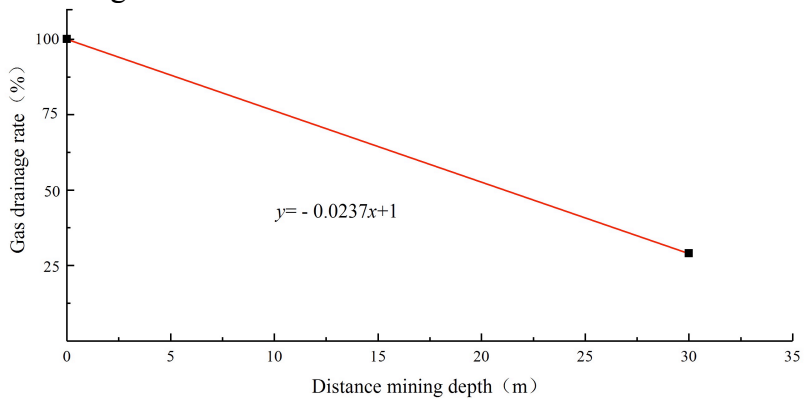

Fig. 5. Lower coal discharge rate and distance between the relationship 
$y=-0.0237 x+1$

where $y$ is the gas emission rate of the lower coal seams (\%) and $x$ is the vertical distance between the lower coal seams and mining level $(\mathrm{m})$.

The preceding test of gas emission rate was conducted after gas extraction, which was not performed on all lower coal seams before stoping of the working face. However, the relationship between gas content in lower coal seams of the mining layer and distance could be disclosed according to direct testing of gas content in the $45 \#$ coal seam on the $+500 \mathrm{~m}$ level. Furthermore, the relationship between gas content and buried depth can be deduced, according to Chongqing Coal Science Institute.

$X_{i}=0.0163 x+5.21$

Equation (4) promoted gas emission prediction in the adjacent layers to gas emission prediction in the lower coal seams, which approximately demonstrates a uniform continuity. Gas emission in the lower coal seams is analyzed by constructing a geometric model (Fig. 6). Suppose that the vertical thickness $x \mathrm{~m}$ away from the stratified mining is $d x \mathrm{~m}\left(\cos ^{-1} \alpha \mathrm{d} x\right.$ along the tilt thickness), the gas content in coal seams is $X_{i}$, and the emission rate is $\lambda_{i}$. The gas content in the lower coal seams and gas emission rate in the pressure relief coal seams can both be expressed by the vertical distance to the mined layer. Suppose the two parameters conform to the linear relationship

$X_{i}=X_{t} x+X_{0}$

$\lambda_{i}=\frac{1}{h_{p}} x+1.0$

where $X_{i}$ is the gas content in the coal seams at $x$ depth of the stratified mining $\left(\mathrm{m}^{3} / \mathrm{t}\right), x$ is the distance to the stratified mining $(\mathrm{m}), X_{i}$ is the gas content gradient $\left(\mathrm{m}^{3} / \mathrm{t} \cdot \mathrm{m}\right), X_{0}$ is the gas content in stratified mining and in the lowest elevation $\left(\mathrm{m}^{3} / \mathrm{t}\right)$, and $h_{p}$ is the failure depth influenced by mining activity $(\mathrm{m})$.

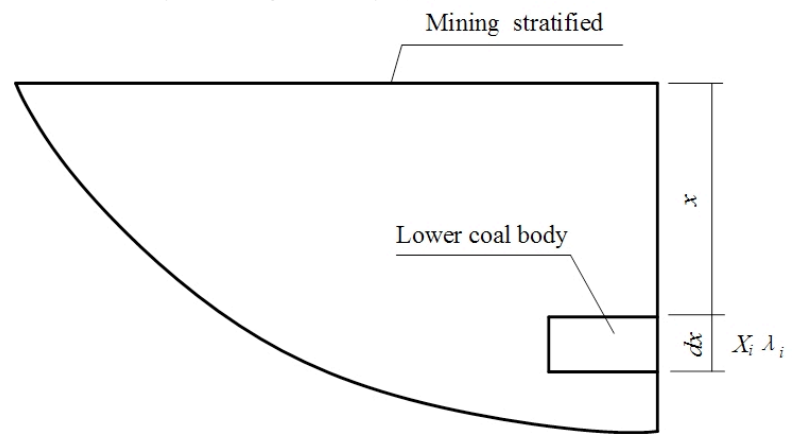

Fig. 6. The lower part of the coal gushes out to analyze the geometric model

Combined with Equation (4) and the corresponding geometric model, the gas emission volume in the lower coal seams can be expressed as:

$$
\begin{aligned}
q_{3} & =\sum_{i=1}^{h_{p} / d x} \frac{\sin ^{-1} \alpha d x}{M} \lambda_{i}\left(X_{i}-X_{c}\right) \\
& =\int_{0}^{h} \frac{1}{M} \lambda_{i}\left(X_{i}-X_{c}\right) \sin ^{-1} \alpha d x
\end{aligned}
$$

$$
q_{3}=\frac{1}{M} \sin ^{-1} \alpha\left(\frac{\left(X_{0}-X_{c}\right)}{2} h_{p}+\frac{X_{t}}{6} h_{p}{ }^{2}\right)
$$

where $M$ is the height of the horizontal section (m), $X_{c}$ is the gas content in the residual coal seam $\left(\mathrm{m}^{3} / \mathrm{t}\right)$, and $\alpha$ is the coal seam dip angle $\left(^{\circ}\right)$.

Relevant data on the west wing face in the $45 \#$ coal seam is as follows: height of the horizontal section $M=25 \mathrm{~m}$, gas content gradient $X_{T}=0.016$, original gas content $X=5.21$ $\mathrm{m}^{3} / \mathrm{t}$, gas content in residual coal seam $X_{c}=1.53$, failure depth influenced by mining $h_{p}=30 \mathrm{~m}$, and coal seam dip angle $\alpha=45^{\circ}$. These data are brought into Equation (11); therefore, the relative gas emission volume of the lower coal seams of the mining layer $\left(q_{3}\right)$ is obtained as follows:

$q_{3}=2.31 \mathrm{~m}^{3} / \mathrm{t}$

\subsection{Gas emission volume in the old goaf}

Limited by the stratified working faces and mining technologies during stratified mining of steep seams, abundant residual coals were retained in the old goaf. Under the ventilation negative pressure on the working face, gas in the old goaf entered the stope face through the mining fractures. Consequently, gas emission on the working face also covered the gas emission in the old goaf. Given that testing gas emission in the old goaf was difficult, the gas emission coefficient on the working face was calculated as follows:

$q_{4}=K^{\prime}\left(q_{1}+q_{2}+q_{3}\right)$

where $q_{4}$ is the gas emission volume in the old goaf $\left(\mathrm{m}^{3} / \mathrm{t}\right)$ and $K^{\prime}$ is the gas coefficient in the old goaf and has no measured value. The reference values of $K^{\prime}$ are $0.15-0.25$, which uses the low value under high ventilation management level and the high value under low ventilation management level. $K^{\prime}$ is set 0.15 for the west wing of the 45 \# coal seam at the $+575 \mathrm{~m}$ level.

Therefore, the gas emission volume on the working face is predicted as follows:

$q_{4}=K^{\prime}\left(q_{1}+q_{2}+q_{3}\right)=0.81 \mathrm{~m}^{3} / \mathrm{t}$

According to predictions of different gas emission sources on the working face, the total gas emission volume on the working face is $6.24 \mathrm{~m}^{3} / \mathrm{t}$. The composition is shown in Table 6 .

Table. 6. Gas emission constitutes

\begin{tabular}{l|l|l}
\hline Name & $\begin{array}{l}\text { Emission quantity } \\
\left(\mathrm{m}^{3} / \mathrm{t}\right)\end{array}$ & $\begin{array}{l}\text { Proportion } \\
\mathbf{( \% )}\end{array}$ \\
\hline Mining stratification & 2.95 & 47.27 \\
Adjacent Seams & 0.17 & 2.72 \\
Lower coal body & 2.31 & 37.03 \\
Upper old goaf & 0.81 & 12.98 \\
Total & 6.24 & 100.00 \\
\hline
\end{tabular}

The absolute gas emission volume on the working face was proportional to the yield of the working face. Given the high yield of the working face, the absolute gas emission volume is also high. The predicted absolute gas emission volume on the west wing of the $45 \#$ coal seam at the $+575 \mathrm{~m}$ 
level under different yields can be calculated according to Equation (13):

$$
q_{\text {mining } j}=q_{\text {mining }} \times \frac{\mathrm{A}}{1440}
$$

where $q_{\text {mining }}$ is the absolute gas emission volume on the working face $\left(\mathrm{m}^{3} / \mathrm{min}\right), q_{\operatorname{mining}}$ is the relative gas emission volume on the working face $\left(6.24 \mathrm{~m}^{3} / \mathrm{t}\right)$, and $\mathrm{A}$ is the daily output on the working face $(\mathrm{t} / \mathrm{d})$.

According to Equation (13), predicted results of the absolute gas emission volume on the west wing of $45 \#$ coal seam at the $+575 \mathrm{~m}$ level under different yield conditions can be obtained, as shown in Fig. 7.

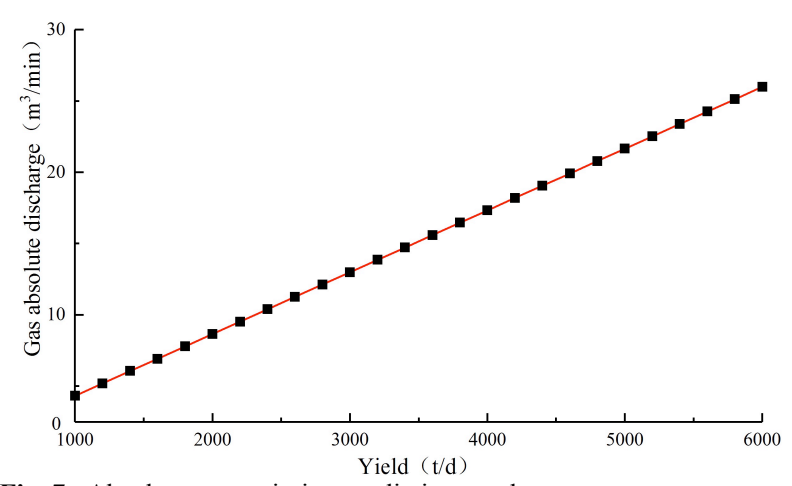

Fig. 7. Absolute gas emission prediction results

\section{Result Analysis and Discussion}

\subsection{Model prediction results comparison}

According to yield and gas emission statistics during the stoping period of Wudong Coal Mine, the average daily yield is $2266.5 \mathrm{t}$ and the gas emission volume in production practices is $9.04 \mathrm{~m}^{3} / \mathrm{min}$. The practical recovery rate and daily yield data were brought into the new prediction model of gas emission volume, thereby obtaining its prediction data. Relevant data on the steep seam was brought into the standard different source prediction method to verify the accuracy of the new model, and three groups of gas emission data were compared. Comparison results are shown in Table 7.

Table 7. Comparison results between the actual gas emission and the predicted gas emission

\begin{tabular}{l|l|ll}
\hline $\begin{array}{l}\text { Gas emission prediction } \\
\text { method }\end{array}$ & $\begin{array}{l}\text { Absolute amount } \\
\left(\mathrm{m}^{3} / \mathrm{min}\right)\end{array}$ & $\begin{array}{l}\text { Prediction error } \\
(\%)\end{array}$ \\
\hline $\begin{array}{l}\text { New gas emission } \\
\text { forecasting method source } \\
\text { Standard } \\
\text { prediction method } \\
\text { Actual gas emission }\end{array}$ & 9.82 & +8.63 & \\
\hline
\end{tabular}

The gas emission volume on the working face of the steep seam in Wudong Coal Mine was predicted negative $\left(-0.36 \mathrm{~m}^{3} / \mathrm{t}\right)$ by existing source prediction methods, which reported negative gas emission volume on the working face of the steep seam $\left(-0.36 \mathrm{~m}^{3} / \mathrm{t}\right)$. The prediction results evidently disagrees with production practices. The error between the model result and actual gas emission volume is small $(+8.63 \%)$, indicating that the proposed prediction method was reasonable. This finding also proved that the previous hypothesis, which stated the reduction trend of the gas emission rate along the rock formation, was reasonable.

\subsection{Error analysis}

As can be seen from Table 4.1, based on the standard source-based prediction method, the error is mainly caused by the following reasons, and the analysis is as follows:

(1) The working face length of steep seam during the stratified mining is equal to the horizontal thickness of the coal seam. The working face is relatively short. If the influence coefficient $\left(K_{3}\right)$ of walkthrough gas in the preparatory working in the mining area on gas emission of coal seams is calculated with reference to Prediction Methods of Gas Emissions in Mine Wells [30], then this method is often used to acquire negative influence coefficient.

(2) According to gas emission characteristics and sources on stoping technology and working face in steep seams, relevant standards lack references to predict gas emission in lower coal seams and the top old goaf, especially the former one. It is mainly manifested by the following:

Given that the gas content in steep seams along the inclination direction is positively related to buried depth, the pressure relief gas in a certain range of lower coal seams on the working face may rush to the mining space to different extents. The calculation error based on a simple fixed value of gas content is too large to represent dynamic changes in gas emission.

Buried depth of the coal seam and mining depth of the well determine the number of layers in steep seams. When a large number of layers exist, the gas emission coefficients of each layer $\left(K_{f i}\right)$ cannot be determined according to conventional situations.

The horizontal stratified mining of the thick coal seam is one of the existing prediction methods of gas emission volume in wells. Limited by coal seam thickness, $K_{f i}$ of the upper layer is higher than that of the lower layers. Nevertheless, coal seam thickness along the inclination can be viewed as infinite during stratified mining of the steep seam. During upper mining, gas is released by pressure relief in the lower layer. Meanwhile, during mining of lower layers, high gas content, which is not influenced by mining of the upper layer, may flow upward and supply gas to the upper coal seams. The calculation of gas emission volumes during stratified mining of the steep seam cannot directly use $K_{f i}$. This finding needs further study.

(3) After the mining of steep seams, the roof and floor may develop swelling deformation, resulting in the growth of gas permeability in adjacent layers. The pressure relief gas of the adjacent coal layer is emitted by pressure difference from the mining space through the cracks due to the ventilation negative pressure in the mining space. In addition, the lower coal seams may be influenced by mining activities; therefore, gases in the lower coal seams flow to the working space through mining cracks. This gas emission source is not calculated in the existing prediction methods.

(4) Different geological occurrence conditions and physical property parameters of coal seams in various mine areas and relevant mining parameters may cause different pressure relief ranges and gas emission volumes of the lower coal seams in the stope face. Thus, calculation of gas emission volume on the stratified mining faces in one well should be adjusted and optimized according to coal seam and geological conditions in different regions. 


\section{Conclusions}

To establish a prediction model of gas emission quantity applicable to horizontally layered mining of steep seams, we predicted gas emission quantity from the coal body below the mined bed and that from the old goaf at the upper layer by using the different-source prediction method. The results calculated through the new model were acquired based on field data in Wudong Coal Mine and compared with results obtained through existing standard different-source prediction methods. The following main conclusions were finally drawn:

(1) The different source prediction method can predict various gas sources, gas emission volumes from different sources, and emission laws on varying working faces. However, the gas emission law in steep seams is relatively distinct. Existing different source prediction models of gas emissions cannot meet in-situ prediction demands and must be optimized according to specific goals.

(2) According to gas emission characteristics on the stratified mining faces in steep seams, the newly constructed prediction model considered pressure relief gas emission in the lower coal seams and gas emission in the upper old goaf. Results demonstrate that the proposed prediction method has a small error with an actual value $(+8.63 \%)$, which conforms to practical situations in stratified mining of gas emission in steep seams.
The gas prediction model formula of a steep seam proposed in this study is clear with simple form, easy determination of parameters and easy procedural implementation. In addition, it can predict gas emission quantities in four parts, namely, mining layer, adjacent layer, lower coal body, and upper old goaf, thus laying a foundation for further analysis of gas emission disasters in the horizontally layered mining of steep seams. However, under the influences of coal seam conditions and geological features, small errors exist between the obtained calculation results and actual gas emission quantity. Therefore, future studies should analyze the factors influencing these errors to improve the prediction accuracy of gas emission quantity in the horizontally layered mining of steep seams.

\section{Acknowledgments}

The study was supported by the 13th Five-Year National Science and Technology Major Project-The Development and Utilization Technology of Coalbed Methane in the Large Inclined Angle Multi-coal Coal Mine Area of Xinjiang (Project No. 2016ZX05043-005).

This is an Open Access article distributed under the terms of the Creative Commons Attribution License

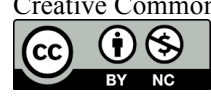

\section{References}

1. Xie, Q., "The Theory and Its Application on Coal Mining and Gas Extraction in Outburst coal seams of Steeply". Doctoral Dissertation of Central South University, China, 2013, pp.22-27.

2. Zhang, D., Liu, H., Fan, G., Wang, X., "Connotation and prospection on scientific mining of large Xinjiang coal base". Journal of Mining and Safety Engineering, 32(1), 2015, pp. 1-6.

3. Tu, H., Tu, S., Bai, Q., Yuan, Y., "Instability of a coal pillar section located at a steep mining face: Pillar size selection". Journal of China University of Mining \& Technology, 42(1), 2013, pp.6-11.

4. Noack, K., "Control of gas emissions in underground coal mines". International Journal of Coal Geology, 35(1-4), 1998, pp.57-82.

5. Yu, Q., "Coal mine Gas Control". Xuzhou: China University of Mining and Technology Press, China, 1992, pp.5-6.

6. Wang, G., Wu, M., Cheng, W., Chen, J., Du, W., "Analysis of energy conditions for coal and gas outburst and factors influencing outburst intensity". Rock and Soil Mechanics, 36(10), 2015, pp.2974-2982.

7. Wang, G., Wu, M., Wang, H., Huang, Q., Zhong, Y., "Sensitivity Analysis of Factors Affecting Coal and Gas Outburst Based On A Energy Equilibrium Model". Chinese Journal of Rock Mechanics and Engineering, 34(02) 2015, pp. 238-248.

8. Wang, R., Xiu, Y., Wang, G., Wu, M., Du, W., "Numerical Simulation of Coal and Gas Outburst Based on Particle Flow Theory". Journal of Shandong University of Science and Technology (Natural Science) , 35(04) 2016, pp. 52-61.

9. Yu, B., "Technical Manual for Coal Mine Gas Disaster Prevention and Utilization". Beijing: China Coal Industry Publishing House, China, 2005, pp.10-12.

10. Yu, Q., Wang, K., Yang, S., "Study on Pattern and Control of Gas Emission at Coal Face in China". Journal of China University of Mining \& Technology, 29(1), 2000, pp. 9.

11. Lunarzewaski, L., "Gas emission prediction and recovery in underground coal mines". International Journal of Coal Geology, 35(1), 1998, pp. 117-145.

12. Karacan, C.O., Olea, Ricardo A., "Geostatistical modeling of the gas emission zone and its in-place gas content for Pittsburgh-seam mines using sequential Gaussian simulation”. International Journal of Coal Geology, 90-91, 2012, pp. 50-71.

13. Liu, Y., Xue, W., Li, Z., "Problems and Correction of Gas Emission Prediction Model in Mine Statistical Method". Safety in Coal Mines, 46(05), 2015, pp. 176-178+182.
14. Palchik, V., "Estimation of methane emission from shallow gasbearing sandstones". Engineering Geology, 245, 2018, pp. 33-43.

15. Hu, Q., Zou, Y., Wen, G., Zhao, Xu., "New technology of outburst danger prediction by gas content". Journal of China Coal Society, 32(03), 2007, pp. 276-280.

16. Dai, G., Wang, Y., Zhang, C., Li, Q., Shao, G., "Forecast of the gas effused from the face in protective seam". Journal of China Coal Society, 32(4), 2007, pp.382.

17. Huang, W., Tong, M., Ren, Z., "No nlinear Combination Fo recast of Gas Emission Amount Based on SVM". Journal of China University of Mining \& Technology, 38(02), 2009, pp.234-239.

18. Zhang, Z., Yuan, C., "Study on mathematical model of coalbed gas geology used to prediction of mine gas emission". Journal of China Coal Society, 24(4), 1999, pp.368.

19. Lv, F., Liang, B., Sun, W., Wang, Y., "Gas emission quantity prediction of working face based on principal component regression analysis method". Journal of China Coal Society, 37(01), 2012, pp.113-116.

20. He, L., Shi, S., Song, Y., Liu, Y., "Complexity and measure ment of complex degree of gas gush in heading faces of coal mine". Journal of China Coal Society, 33(5), 2008, pp.547.

21. Dougherty, Heather N., Karacan, C.O., "A new methane control and prediction software suite for longwall mines". Computers \& Geosciences, 37(9), 2011, pp.1490-1500.

22. Li, S., Ma, Y., Lin, H., Pan, H., Zhao, P., "Selection of gas emission prediction index based on factor analysis". Journal of Xi An University of Science and Technology, 37(04), 2017, pp.461466.

23. Guo, D., Zheng, M., Ju, C., Hao, X., “Stepwise regression method for predicting gas emission from coal faces". Journal of University of Science and Technology Beijing, 31(09), 2009, pp.1095-1099.

24. Booth, P, Brown, H, Nemcik, J., Ting, R., "Spatial context in the calculation of gas emissions for underground coal mines". International Journal of Mining Science and Technology, 27(05), 2017, pp.787-794.

25. Moraru, R, I., Babut, G, B., Cioca, L I., "Study of methane flow in caved goafs ajacent to longwall faces in Valea Jiului coal basin". International Multidisciplinary Scientific GeoConference: SGEM: Surveying Geology \& mining Ecology Management, 1, 2013, pp.731. 
Huang Xuchao, Fan Cheng, Wang Rui and Yan Guoqiang/

Journal of Engineering Science and Technology Review 12 (2) (2019) 17 - 26

25. Moraru, R, I., Babut, G, B., Cioca, L I., "Study of methane flow in caved goafs ajacent to longwall faces in Valea Jiului coal basin". International Multidisciplinary Scientific GeoConference: SGEM: Surveying Geology \& mining Ecology Management, 1, 2013, pp.731.

26. Fan, B., Bai, C., Li, J., "Forecasting model of coalface gas emission based on LMD-SVM method". Journal of Mining and Safety Engineering, 30(06), 2013, pp.946-952.

27. Hu, K., Wang, S., Han, S., Wang, S., "Gas Emission Quantity Prediction of Working Face Based on TLBO-LOIRE Method". Journal of Basic Science and Engineering, 25(05), 2017, pp.10481056.
28. Fu, H., Xie, S., Xu, Y., Chen, Z., "Gas emission dynamic prediction model of coal mine based on ACC-ENN algorithm". Journal of China Coal Society, 39(07), 2014, pp.1296-1301.

29. Li, Z., Meng, X., "Prediction of mine gas emission". Journal of Liaoning Technical University (Natural Science), 33(09), 2014, pp.1212-1216.

30. Industry Standards for Safety Production of the People's Republic of China., "Standard in Prediction method of mine gas emission rate: AQ1018-2006". Beijing: State Administration of Work Safety Press, China, 2006, pp.153-162. 